\title{
Credit Management and Financial Decision-Making in the Agricultural Portfolio of Universal Banking
}

\author{
Carlos Robles-Julio ${ }^{1 *}$, Geomar Molina Bolivar² and Iris Jiménez Pitre ${ }^{2}$ \\ 1Universidad de La Guajira, Colombia; croblesjulio@uniguajira.edu \\ ${ }^{2}$ Grupo de Investigación BIEMARC, Universidad de La Guajira, Colombia; \\ gmolina@uniguajira.edu,coiajimenez@uniguajira.edu.co
}

\begin{abstract}
Objective: To determine the relationship between credit management and decision-making of the agricultural portfolio of universal banking in the municipality of Maracaibo, Zulia State, Venezuela. Materials and Methods: by means of a descriptive, correlational research and field, with a non-experimental design, we studied the management of credits selected by the middle of the banking 2014, Rankin with a population-based sample composed of five (5) managers, to which they applied a validated instrument of ten experts and high reliability according to the Alpha-Cronbach coefficient $(\alpha=0.85)$. Finding: The results determine a positive relationship, from the results of the Spearman correlation coefficient $(r=0.49)$, which is evidence of a moderate implementation of credit management for financial decision-making. Applications: It is necessary to develop alternatives to take decisions related to the credit and the procedures for granting through ideas.
\end{abstract}

Keywords: Agricultural Portfolio, Credit Management, Decision-Making, Universal Banking

\section{Introduction}

The management of credits is fundamental for the banking institutions because financial intermediation is one of its main functions, in virtue, that when granting a credit, results in an impulse to the development and growth of the borrower, as well as the environment, as well as society in general; this is achieved through the acceptance of customer deposits, then turns to the same loans or to other clients, taking into account the active passive - offered under agreements governed by rules and procedures, with the purpose of addressing effectively the obligations of both parties. The financial sector in Venezuela, to date, is composed of 55 institutions, of which 45 are of private capital and 10 are of the State, of these, between $75 \%$ and $80 \%$ of the operations are concentrated in the 10 major financial institutions, who also own $73.5 \%$ of total assets, the $73.1 \%$ of profits and $76.6 \%$ of the appropriations granted to the banking sector as a whole.
It should be noted that the main revenue from financial institutions, come from the yield obtained, by the accrued interest depending on the placement of credit operations, for this is necessary in the first completed an evaluation of the client to which you will be given credit, to ensure recovery of the same, this being the purpose of the institutions. Through the provision of financial resources, banks are in pursuit of the increase of benefits in society, in the production of goods and services in the market, which facilitates the creation and expansion of the production of commercial or industrial companies, which translates into a contribution directly to the development of productive activities in the country.

All the activity of banking nature is an enhancer of a country's economy, since the bank receives funds from the public, to turn them into credit operations. This becomes a situation of financial intermediation, through which the institution takes money inoperative, and places it in credit investments. It should be noted that in spite 
of technological advance, the agricultural sector depends on the relationship between man and nature, since most of the agricultural activities, livestock, forestry and fisheries are developed directly in natural environments. The agricultural sector is one of the fundamental axes for the development of any country; from a strategic point of view, agriculture requires legal measures, economic, financial, environmental, educational, among others, in order to encourage investment and ensure the return of the same ${ }^{1}$.

In this regard, each government creates or modifies the public lending agencies to support agriculture. From several decades ago, the Venezuelan State has intervened directly in the private banking, by imposing minimum amounts of agricultural financing, both of interest rate as percentage allocation to the agricultural portfolio. In this connection it should be noted that the variable financial decision-making goes hand in hand with the credit management, as this depends on the process of granting credits to the area of agricultural portfolio, taking into account the legal framework by which they are governed; currently it is worth mentioning that it is a sector that is monitored and strictly regulated in rates, terms and destinations of the funds. The intermediation provides to society in general of means of payment, through these, will make it easier, the much-needed exchange of goods or services, guaranteeing the profitability and productivity of the credit management, through its supervisory role also and regulator. In this sense, the agricultural loan is a loan designed to meet the needs of funding in the short, medium and long-term needs of the agricultural sectors of plants, animals, agricultural, forestry, fisheries and aquaculture $e^{2,3}$. The amount is set according to the requirements established for each item, considering equally, the guarantees offered by the applicants and other elements that allow in a predictable manner and accounting, minimize credit risk.

People make decisions in organizations and the quality of options you choose are affected primarily by their perceptions ${ }^{4}$. In the case of the credit management, this will be influenced by the requirements of the banking entities, securities received or offered by customers, by effects of the impact of economic indicators, among other aspects, worthy of consideration, identify and evaluate. Of the above, it is clear from the rational use of a good financial decision-making, that allow an efficient and effective credit management, not only for the purposes of the bank as financing entity, but also for the purpose of increasing the country's productive apparatus, and promote economic growth and social development, through the areas that represent items of first necessity as are the agricultural area, to this end it is essential, to analyze the credit management in the area mentioned above and how this is affected by the decision-making process.

Universal banking is characterized by the concentration of various organizational activities and financial services in the same physical entity, being multiple the advantages that are attributed to the schemes of universal banking, such as the quantitative reduction of costs which is derived from its implementation, given the physical concentration of the business; also the possibility to attract or retain customers on the basis of the provision of a greater range of financial services or on the basis of the professional reputation in a particular financial activity ${ }^{5}$. By virtue of the great importance that represents the credit management for the country's development, especially in the agricultural sector, resulting in an improved quality of life in society, represented benefits for the issuing bank of credit and for the economy in general. In this regard, the financing of farming is based on the need to understand and differentiate the Agricultural Sector to other sectors of the economy, due to the dependence of the environment and the risk and uncertainty to which they are subject. It is raised to characterize, credit management and decision-making, so as to determine the relationship between these two variables, in the agricultural portfolio of universal banking in the municipality of Maracaibo, Zulia State, Venezuela.

\section{Materials and Methods}

A descriptive method in the field: non-experimental, for key variables, credit management and financial decision-making, in its different dimensions and indicators (Table 1). For this, five (5) credit managers selected by the middle of the banking ranking 2014, five (5) first universal banks members of the Department of Agricultural Credit (Banco de Venezuela, Provincial, Banesco, commercial, and West Bank off); whose senior managers (managers) formed the information units $(\mathrm{n}=5)$.

For the study of the variables, during the period January-July of the year 2015, a survey was carried out to managers of the five banking institutions studied, by means of a questionnaire with a total of 63 items, with five (5) alternative answers, which were always (S), almost 
Table 1. Variables, dimensions and indicators studied in the agricultural portfolio of banking institutions studied in the municipality of Maracaibo, Zulia State, Venezuela

\begin{tabular}{|c|c|c|c|}
\hline A Variable & Dimension & Sub-dimension & Indicators \\
\hline \multirow{4}{*}{$\begin{array}{l}\text { Credit } \\
\text { Management }\end{array}$} & \multirow{3}{*}{ Credit Management } & $\begin{array}{l}\text { Basic factors which determine } \\
\text { the risk in the granting of credit }\end{array}$ & \begin{tabular}{|l} 
Character \\
Ability \\
Capital \\
Terms and Conditions \\
\end{tabular} \\
\hline & & Credit Request & \begin{tabular}{|l|} 
Natural Person \\
Legal Person \\
\end{tabular} \\
\hline & & \begin{tabular}{|l|}
$\begin{array}{l}\text { Analysis of the credit } \\
\text { application }\end{array}$ \\
\end{tabular} & \begin{tabular}{|l|} 
Qualitative information \\
Quantitative information \\
\end{tabular} \\
\hline & $\begin{array}{l}\text { Standards used for the management } \\
\text { of agricultural portfolio }\end{array}$ & - & $\begin{array}{l}\text { The Policies and Procedures Manual } \\
\text { Legal Norms } \\
\text { Regulation } \\
\end{array}$ \\
\hline \multirow[t]{2}{*}{$\begin{array}{l}\text { Financial } \\
\text { Decisions }\end{array}$} & The decision-making process & - & $\begin{array}{l}\text { Identify the problem } \\
\text { Identify the decision criteria } \\
\text { Assign weights to the criteria } \\
\text { Develop the alternatives } \\
\text { Analyze alternatives } \\
\text { Selecting an Alternative } \\
\text { Implement the alternative } \\
\text { Evaluate the effectiveness of the decision }\end{array}$ \\
\hline & Conditions for decision-making & - & \begin{tabular}{|l|} 
Certainty \\
Risk
\end{tabular} \\
\hline
\end{tabular}

always (CS), Sometimes (AV), almost never (CN), and Never (N) (Arias, 2015), which were applied a weighted score of 5, 4, 3, 2 and 1 respectively. The instrument (questionnaire) was validated by ten (10) experts and its reliability was determined according to the coefficient Alpha-Cronbach, which presented, according to its value $(\alpha=0.85)$, a high reliability ${ }^{6}$.

The valuation of the options was conducted to quantify the opinions of respondents, to finally categorize the characteristics assessed by means of a range of values, these being specifically High Compliance (3.67 - 5), Medium Compliance (2.34 - 3.66), and low compliance $(1-2.33)^{6}$. It was considered only to that presented high compliance as those features that if they have the attribute, while those that presented the medium and low compliance were considered with the absence of the same. The results are expressed by means of the descriptive statistics, absolute frequency (n), relative frequency (\%) and the average. In addition: applied a Spearman correlation coefficient, to see if there is a relationship between the two main variables studied by means of the program SPSS Statistics 24.0.

\section{Results and Discussion}

In the Table 1 shows the behaviour of the responses on the basis of the sub-dimension basic factors which determine the risk in the granting of credit, and each of the indicators that comprise it, in this sense, the character indicator showed that $33.3 \%$ placed in each one of the alternatives in response almost never and sometimes respectively, being the most frequent, for an average of 2.6 which qualifies the medium compliance indicating the absence of the attribute. Based on this evidence, that sometimes the character for the granting of credit measures the level of commitment of payment, as well as also notes that occasionally sets empirically the reputation of payment. The foregoing is consistent with what was expressed by those who mention that the character on a credit risk comprises the set of qualities of the subject that they do want to pay at maturity of a debt. Honesty is one of the basic qualities of character, in addition to the integrity, impartiality, responsibility, and trust ${ }^{7}$.

With regard to the capacity indicator, a $43.3 \%$ of the subjects surveyed was inclined to the alternative of almost 
always and $33.3 \%$ opted for the option to always, obtaining an average of 4.03 Noting high compliance is considered as well the presence of the attribute; which indicates that the credit capacity measures the possibility of paying a debt at maturity, on the other hand the capacity to pay is diminished by the expenditure at the time of the credit management, and this capacity is affected by the time limit, since a long-term obligation cannot be achieved in the short term, which is described as Credit capacity, it means the possibility or ease to pay a debt at maturity. However, the willingness and desire to pay of the debtor, if you do not have the money to make the payment, is facing a risk. With respect to capital, $86.7 \%$ answered the Always option, resulting in an average of 4.87 cataloguing a high level of compliance and the presence of the attribute. Demonstrating that capital measures the level of indebtedness of the applicant for credit; it being understood by capital, the financial strength of an applicant for credit as measured by the equity in your business ${ }^{7}$.

In relation to the indicator conditions, $43.3 \%$ of respondents and positioned in the option of almost always, while a $23.3 \%$ opted for the alternatives of sometimes and almost never in each respectively, with an average of 3.27 pointing to a medium compliance and absence of the attribute (Table 1). Indicating that, in the universal bank in Maracaibo sometimes the decision-making process lacks control, and can alter the conditions of the loan portfolio in the agricultural sector. Sometimes the conditions of competition in an industry influence the assessment of credit risk.

The results differ from the approach that points out that by very credible that can be considered an individual from the point of view of his character, capacity and capital, may not always be a good business to extend credit ${ }^{7}$. Confidence in the credit does not depends entirely on the factors inherent to the risk and on which it is presumed that the applicant has control; in part, it also depends on the economic, which always involves risk. In summary, we obtained a $31.7 \%$ in the alternative always, $30 \%$ of the opinion almost always and a $18.3 \%$ leaned by the option at times, with an average of 3.69 which demonstrated a high compliance and the presence of the basic Factors that determine the risk (FBR) in the granting of credit in the universal bank in Maracaibo (Table 2).

Table 3 corresponds to the sub-dimension credit application, the indicator natural person submitted that a 53.3\% of the subjects surveyed leaned by the alternative at times, being the most frequent, which was an average of 2.93 which categorizes the medium compliance, thus indicating the absence of the attribute. This shows that in a moderate lending to the agricultural sector for natural person, is done by gathering all of the requirements demanded by the financial institution, sometimes the staff of the department differs with respect to the requirements of the Farming Sector, and occasionally the processing of credit management applies making Exceptions of appropriation of collections for natural persons.

With regard to the legal person a $46.7 \%$ indicated the alternative sometimes, for its part, the $23.3 \%$ of the subjects respondents focused on the alternative of almost always; the average stood at 3.27 which indicates the medium compliance and reflects the absence of the attribute (Table 3). Demonstrating that the granting of credits to the legal figure is performed on occasions requesting all the requirements demanded by the financial entity. Sometimes the management of credit depends on the legal requirements to the agricultural sector for the granting of the loan. Similarly, occasionally the processing of funding to the applicant applies making exceptions of appropriation of collections for

Table 2. Absolute Frequency (n), relating (\%), stockings and categories of the FBR in the granting of agricultural credit in banking institutions studied in the municipality of Maracaibo, Zulia State, Venezuela

\begin{tabular}{|l|c|c|c|c|c|c|c|c|c|c|c|l|}
\hline \multirow{2}{*}{ Indicators } & \multicolumn{2}{|c|}{ S } & \multicolumn{2}{c|}{ CS } & \multicolumn{2}{|c|}{ AV } & \multicolumn{2}{c|}{ CN } & \multicolumn{2}{|c|}{$\mathbf{N}$} & \multirow{2}{*}{ Media } & \multirow{2}{*}{ Category } \\
\cline { 2 - 13 } & $\mathbf{N}$ & $\mathbf{\%}$ & $\mathbf{N}$ & $\mathbf{\%}$ & $\mathbf{N}$ & $\mathbf{\%}$ & $\mathbf{N}$ & $\mathbf{\%}$ & $\mathbf{N}$ & $\mathbf{\%}$ & & \\
\hline Character & 0.0 & 0.0 & 2.0 & 20.0 & 3.3 & 33.3 & 3.3 & 33.3 & 1.3 & 13.3 & 2.60 & Medium compliance \\
\hline Ability & 3.3 & 33.3 & 4.3 & 43.3 & 1.7 & 16.7 & 0.7 & 6.7 & 0.0 & 0.0 & 4.03 & High Performance \\
\hline Capital & 8.7 & 86.7 & 1.3 & 13.3 & 0.0 & 0.0 & 0.0 & 0.0 & 0.0 & 0.0 & 4.87 & High Performance \\
\hline Terms and Conditions & 0.7 & 6.7 & 4.3 & 43.3 & 2.3 & 23.3 & 2.3 & 23.3 & 0.3 & 3.3 & 3.27 & Medium compliance \\
\hline FBR & $\mathbf{3 . 2}$ & $\mathbf{3 1 . 7}$ & $\mathbf{3 . 0}$ & $\mathbf{3 0 . 0}$ & $\mathbf{1 . 8}$ & $\mathbf{1 8 . 3}$ & $\mathbf{1 . 6}$ & $\mathbf{1 5 . 8}$ & $\mathbf{0 . 4}$ & $\mathbf{4 . 2}$ & $\mathbf{3 . 6 9}$ & High Performance \\
\hline
\end{tabular}

S: Always, CS: Almost always, AV: Sometimes, CN: Almost Never, N: Never 
Table 3. Absolute frequency (n) and relative (\%) of the dimension credit application and its indicators in banking institutions studied in the municipality of Maracaibo, Zulia State, Venezuela

\begin{tabular}{|l|c|c|c|c|c|c|c|c|c|c|c|l|}
\hline \multirow{2}{*}{ Indicators } & \multicolumn{2}{|c|}{$\mathbf{S}$} & \multicolumn{2}{|c|}{ CS } & \multicolumn{2}{|c|}{ AV } & \multicolumn{2}{c|}{ CN } & \multicolumn{2}{|c|}{$\mathbf{N}$} & \multirow{2}{*}{ Media } & \multirow{2}{*}{ Category } \\
\cline { 2 - 12 } & $\mathbf{N}$ & $\mathbf{\%}$ & $\mathbf{N}$ & $\mathbf{\%}$ & $\mathbf{N}$ & $\mathbf{\%}$ & $\mathbf{N}$ & $\mathbf{\%}$ & $\mathbf{N}$ & $\mathbf{\%}$ & & \\
\hline Natural Person & 0.7 & 6.7 & 1.3 & 13.3 & 5.3 & 53.3 & 2.0 & 20.0 & 0.7 & 6.7 & 2.93 & Medium compliance \\
\hline Legal Person & 1.3 & 13.3 & 2.3 & 23.3 & 4.7 & 46.7 & 1.0 & 10.0 & 0.7 & 6.7 & 3.27 & Medium compliance \\
\hline Credit Application & $\mathbf{1 . 0}$ & $\mathbf{1 0 . 0}$ & $\mathbf{1 . 8}$ & $\mathbf{1 8 . 3}$ & $\mathbf{5 . 0}$ & $\mathbf{5 0 . 0}$ & $\mathbf{1 . 5}$ & $\mathbf{1 5 . 0}$ & $\mathbf{0 . 7}$ & $\mathbf{6 . 7}$ & $\mathbf{3 . 1 0}$ & Medium compliance \\
\hline
\end{tabular}

S: Always, CS: Almost always, AV: Sometimes, CN: Almost Never, N: Never

Table 4. Absolute frequency ( $\mathrm{n}$ ) and relative (\%) of indicators associated with the analysis of the Credit Application Accounting Standards Codification (ASC) in banking institutions studied in the municipality of Maracaibo, Zulia State, Venezuela

\begin{tabular}{|l|c|c|c|c|c|c|c|c|c|c|c|c|l|}
\hline \multirow{2}{*}{ Indicators } & \multicolumn{2}{|c|}{ S } & \multicolumn{2}{c|}{ CS } & \multicolumn{2}{|c|}{ AV } & \multicolumn{2}{c|}{ CN } & \multicolumn{2}{|c|}{ N } & \multirow{2}{*}{ Media } & \multirow{2}{*}{ Cate-gory } \\
\cline { 2 - 11 } & $\mathbf{N}$ & $\mathbf{\%}$ & $\mathbf{N}$ & $\mathbf{\%}$ & $\mathbf{N}$ & $\mathbf{\%}$ & $\mathbf{N}$ & $\mathbf{\%}$ & $\mathbf{N}$ & $\mathbf{\%}$ & & \\
\hline Qualitative information & 1.7 & 16.7 & 5.7 & 56.7 & 2.7 & 26.7 & 0.0 & 0.0 & 0.0 & 0.0 & 3.90 & High Perfor-mance \\
\hline Quantitative information & 7.3 & 73.3 & 1.7 & 16.7 & 0.7 & 6.7 & 0.3 & 3.3 & 0.0 & 0.0 & 4.60 & High Perfor-mance \\
\hline ASC & $\mathbf{4 . 5}$ & $\mathbf{4 5 . 0}$ & $\mathbf{3 . 7}$ & $\mathbf{3 6 . 7}$ & $\mathbf{1 . 7}$ & $\mathbf{1 6 . 7}$ & $\mathbf{0 . 2}$ & $\mathbf{1 . 7}$ & $\mathbf{0 . 0}$ & $\mathbf{0 . 0}$ & $\mathbf{4 . 2 5}$ & High Perfor-mance \\
\hline
\end{tabular}

S: Always, CS: Almost always, AV: Sometimes, CN: Almost Never, N: Never

legal person. In general, the sub-dimension application for credit obtained a $50 \%$ in the alternative at times, the $18.3 \%$ of the opinion almost always and a $15 \%$ leaned by the option almost never, with an average of 3.10 , indicating a medium level of compliance and cataloguing the absence of the attribute (Table 3), noting that sometimes the requests for appropriations do not meet all of the requirements for the granting of the loan of the universal bank in Maracaibo.

Table 4 shows the results for the sub-dimension analysis of the credit application, in which the qualitative information presented a $56.7 \%$ for the alternative of almost always, and $26.7 \%$ felt sometimes, to be the most frequent; with an average of 3.90 indicating a high level of compliance and reflecting the presence of the attribute. Therefore, frequently in the universal bank in Maracaibo, know the qualities allows assessing the information in the financial statements, in the same way, the capabilities to make financial decisions allow for the consideration of the most important aspects of any loan, also provide qualitative information reveals the history of the company in relation to the trajectory of activities carried out by the same.

Similarly, the above results show consistency with qualitative data that focus properly, allowing to evaluate the financial statements, and thus assess the ability of the management, which is one of the most important aspects of the consideration of any loan, that is to say, it refers to the analysis of the background of applicants and the most relevant aspects of its activity transcendental or ${ }^{7}$. With regard to the indicator quantitative information is displayed that the highest percentage was $73.3 \%$ for the alternative of always, with a weight of 4.60 showing a high compliance and the presence of the attribute (Table 4). Often in the universal bank in Maracaibo the quantitative information focuses on providing information to the financial statements, also the financial decision-making is based on the calculation of financial indexes. The financial information is focused through the profit and loss statements, then analyzes the cash generation, that is to say, is based on the calculations of indices of the financial statements of the company through different methods ${ }^{7}$.

In relation to the above-mentioned with regard to the indicators that make up the analysis of credit application, was observed in the alternative always a $45 \%$, while $36.7 \%$ chose the option almost always, and $16.7 \%$ of the view sometimes; with an average of 4.25 demonstrating a high level of compliance and cataloguing the presence of the attribute (Table 4). Evidencing that the universal bank in Maracaibo performs the analysis of credit application, so there is a fulfilment of this parameter. This relates to analyse the credit application the analyst must have and take 
advantage of all the information as possible, in order to form a clear idea of the story, the financial situation and the characteristics of the applicant ${ }^{7}$.

In relation to the Table 5, the results in the sub-dimensions that comprise the credit management dimension, it is noted that the highest percentage was found in the alternative always with a $28.9 \%$, whereas a $28.3 \%$ of the subjects surveyed was directed to the response options almost always and sometimes in each respectively; the average stood at 3.68 indicating a high compliance and cataloguing the presence of the attribute, in relation to the universal bank in Maracaibo is carried out the administration of credit in the agricultural portfolio.

In the dimension standards used for portfolio management and livestock, and each of the indicators that comprise it, show that the manual of standards and procedures a100\% of the subjects surveyed were inclined to the alternative of always, determining an average of 5 that reflects a high level of compliance and indicating the presence of the attribute. This is evidence that it is always used the manual of legal norms issued by the Super Intendancies of banks for lending to agricultural products; in the same way the general rules of universal banking for the management of agricultural credit. Similarly, a $100 \%$ opted for the alternative of always, in relation to the indicator legal norms, obtaining an average of 5 with high compliance, reflecting the presence of this attribute. Demonstrating the application of the rules of procedure of the Central Bank of Venezuela (Banco Central de Venezuela) (BCV) in lending for the granting of credits, in the same way, used the law of institutions in the banking sector and handled the new reforms of the National Assembly of Venezuela in granting loans.

In this regard, the result produced is consistent with the provisions of the regulations of the $\mathrm{BCV}$, which is the entity empowered to regulate the activities or operations carried out by financial institutions. According to official Gazette Number is 40.376, dated 20th March of the year 2014, in its Resolution N 035, laying down the new percentages that must comply with financial institutions in the mandatory credit portfolio of the agricultural sector. In its article 1, the present resolution aims to establish the bases, terms, conditions and mandatory minimum percentages of the credit portfolio that each of the entities of universal banking, as well as the commercial carters that is in process of transformation, both public and private, must devote to the agricultural sector during fiscal year 2014, for the purposes of promoting and strengthening the food sovereignty and security of the nation ${ }^{8}$. With regard to the indicator regulation, the $100 \%$ of respondents chose the option always, with an average of 5 which indicates high compliance and demonstrating the presence of the attribute. It is evident that fully apply the minimum rates laid down in the regulation of the $\mathrm{BCV}$, similarly are carried out by committees established by that Regulation, it will also fulfil the maximum percentage of portfolio growth established.

Venezuelan legislation raises the minimum percentages of the credit portfolio that each of the entities of universal banking, as well as commercial banks, both public and private, shall be required to put on a monthly basis to the agricultural sector during fiscal year 2014. In any case, the percentage of the agricultural loan portfolio for the financing of strategic items may not be less than $60 \%$ of the total portfolio quarterly agrarian. The entities of universal banking, as well as from commercial banks, both public and private, must be placed in medium- and longterm credits a minimum percentage of $20 \%$ of the total agricultural loan portfolio ${ }^{8}$.

Table 5. Absolute frequency ( $\mathrm{n}$ ), relating (\%), stockings and categories of the sub-domains associated with the administration of credit in the banking institutions studied in the municipality of Maracaibo, Zulia State, Venezuela

\begin{tabular}{|l|c|c|c|c|c|c|c|c|c|c|l|l|}
\hline \multirow{2}{*}{ Sub-dimensions } & \multicolumn{2}{|c|}{ S } & \multicolumn{2}{|c|}{ CS } & \multicolumn{2}{|c|}{ AV } & \multicolumn{2}{|c|}{ CN } & \multicolumn{2}{|c|}{ N } & \multirow{2}{*}{ Media } & \multirow{2}{*}{ Category } \\
\cline { 2 - 15 } & $\mathbf{N}$ & $\mathbf{\%}$ & $\mathbf{N}$ & $\mathbf{\%}$ & $\mathbf{N}$ & $\mathbf{\%}$ & $\mathbf{N}$ & $\mathbf{\%}$ & $\mathbf{N}$ & $\mathbf{\%}$ & & \\
\hline Basic factors of risk & 3.2 & 31.7 & 3.0 & 30.0 & 1.8 & 18.3 & 1.6 & 15.8 & 0.4 & 4.2 & 3.69 & High Performance \\
\hline Request Credit Card & 1.0 & 10.0 & 1.8 & 18.3 & 5.0 & 50.0 & 1.5 & 15.0 & 0.7 & 6.7 & 3.10 & Medium compliance \\
\hline $\begin{array}{l}\text { Analysis of the credit } \\
\text { application }\end{array}$ & 4.5 & 45.0 & 3.7 & 36.7 & 1.7 & 16.7 & 0.2 & 1.7 & 0.0 & 0.0 & 4.25 & High Performance \\
\hline Credit Management & $\mathbf{2 . 9}$ & $\mathbf{2 8 . 9}$ & $\mathbf{2 . 8}$ & $\mathbf{2 8 . 3}$ & $\mathbf{2 . 8}$ & $\mathbf{2 8 . 3}$ & $\mathbf{1 . 1}$ & $\mathbf{1 0 . 8}$ & $\mathbf{0 . 4}$ & $\mathbf{3 . 6}$ & $\mathbf{3 . 6 8}$ & High Performance \\
\hline
\end{tabular}

S: Always, CS: Almost always, AV: Sometimes, CN: Almost Never, N: Never 
After analyzing each of the indicators present in the dimension standards used for Portfolio Management and Livestock, reflected that the $100 \%$ of the subjects surveyed ranked in the alternative of always, yielding an average of 5 that indicated a high level of compliance and shows the presence of the attribute; that is, the universal bank in Maracaibo comply fully with the provisions of the regulations on agricultural portfolio, fulfilling the provisions of the Constitution of the Bolivarian Republic of ${ }^{9}$, In his title VI, of the Socio-Economic System, Chapter I, of the Socio-economic regime and the Social Function of the State in the economy, which establishes the promotion of agriculture as a strategic base for rural development, comprehensive and sustainable development of the nation (articles 305 and 306).

In reference to the variable Credit Management, in Table 6 shows that the greatest value obtained was in the alternative always with a $64.4 \%$, whereas a $14.2 \%$ of the subjects surveyed were in favour of each almost always alternatives and sometimes respectively; the average was located in 4.34 demonstrating high compliance and indicating the presence of the attribute, as evidence that the parameters for managing agricultural loan portfolio of the universal bank in Maracaibo. In relation to the above findings are consistent with those obtained by ${ }^{10}$, Who analyzed several financial aspects of banking in the city of Maracaibo, and indicated that financial institutions Credit management handled efficiently by sticking to the legal regulations for the granting of credits, as well as properly managed financial risks. It was observed an improvement in processes with respect to the same aspects of credit management in the agricultural portfolio during the year ${ }^{11}$. The results of this study reveal that in credit management policies implemented by financial institutions, have certain weaknesses due to the lack of knowledge that they possess the employees, using the parameters that must be followed for the granting of agricultural credits. For risk management, it was determined that the methodology used in some is not applied in the right way to measure risk in a portfolio of credits.

In Table 7 the indicator to identify the problem reflects that the $43.3 \%$ of the subjects surveyed was inclined to the alternative of almost always, while $40 \%$ was located in the option sometimes and $10 \%$ felt that always; average was 3.57 which are located in a medium level of compliance and noting the absence of the attribute. In light of the foregoing, reflected that sometimes the formulation of the problem is to achieve a situation different from its original state, it also presents that occasionally the identification of the problem contributes to the development of knowledge in decision-making.

With regard to the indicator to identify the Decision Criteria, $56.7 \%$ of respondents felt almost always, and $40 \%$ ranked option sometimes, obtaining an average of 3.53 demonstrating a medium compliance and the absence of the attribute (Table 7), therefore it is reflected that of moderate way managers determine decision criteria relevant to the taking of a correct decision, in addition to this, they sometimes have criteria to guide its decisions in order to solve problems and sometimes the manager detects a problem through identifying the decision criteria to resolve the situation. Also, the results before raised differ when a manager detects a problem; it has to identify the decision criteria important to resolve it. That is to say, managers need to determine that it is appropriate to make a decision. Be explicit or tacit, managers have criteria to guide its decisions ${ }^{12}$.

With regard to the indicator Assign weights to the criteria a $56.7 \%$ indicated at times, while $33.3 \%$ of the respondents opted for the alternative of almost never, and

Table 6. Absolute frequency (n), relating (\%), stockings and categories of credit management of the agrarian portfolio in banking institutions studied in the municipality of Maracaibo, Zulia State, Venezuela

\begin{tabular}{|c|c|c|c|c|c|c|c|c|c|c|c|c|}
\hline \multirow{2}{*}{ Dimensions } & \multicolumn{2}{|c|}{$\mathbf{S}$} & \multicolumn{2}{|c|}{ CS } & \multicolumn{2}{|c|}{ AV } & \multicolumn{2}{|c|}{$\mathrm{CN}$} & \multicolumn{2}{|c|}{$\mathbf{N}$} & \multirow[b]{2}{*}{ Media } & \multirow{2}{*}{ Category } \\
\hline & $\mathbf{N}$ & $\%$ & $\mathbf{N}$ & $\%$ & $\mathbf{N}$ & $\%$ & $\mathbf{N}$ & $\%$ & $\mathbf{N}$ & $\%$ & & \\
\hline $\begin{array}{l}\text { Administration of the } \\
\text { credit }\end{array}$ & 2.9 & 28.9 & 2.8 & 28.3 & 2.8 & 28.3 & 1.1 & 10.8 & 0.4 & 3.6 & 3.68 & High Compliance \\
\hline $\begin{array}{l}\text { Standards used for the } \\
\text { management agricultural } \\
\text { portfolio }\end{array}$ & 10.0 & 100.0 & 0.0 & 0.0 & 0.0 & 0.0 & 0.0 & 0.0 & 0.0 & 0.0 & 5.00 & High Compliance \\
\hline Credit Management & 6.4 & 64.4 & 1.4 & 14.2 & 1.4 & 14.2 & 0.5 & 5.4 & 0.2 & 1.8 & 4.34 & High Compliance \\
\hline
\end{tabular}

S: Always, CS: Almost always, AV: Sometimes, CN: Almost Never, N: Never 
Table 7. Absolute frequency (n), relating (\%), stockings and categories in the Process for Elements of Implementation (PEI) in banking institutions studied in the municipality of Maracaibo, Zulia State, Venezuela

\begin{tabular}{|c|c|c|c|c|c|c|c|c|c|c|c|c|}
\hline \multirow{2}{*}{ Indicators } & \multicolumn{2}{|c|}{$\mathbf{S}$} & \multicolumn{2}{|c|}{ CS } & \multicolumn{2}{|c|}{ AV } & \multicolumn{2}{|c|}{ CN } & \multicolumn{2}{|c|}{$\mathbf{N}$} & \multirow{2}{*}{ Media } & \multirow{2}{*}{ Category } \\
\hline & $\mathbf{N}$ & $\%$ & $\mathbf{N}$ & $\%$ & $\mathbf{N}$ & $\%$ & $\mathbf{N}$ & $\%$ & $\mathbf{N}$ & $\%$ & & \\
\hline Identify the Problem & 1.0 & 10.0 & 4.3 & 43.3 & 4.0 & 40.0 & 0.7 & 6.7 & 0.0 & 0.0 & 3.57 & $\begin{array}{l}\text { Medium } \\
\text { compliance }\end{array}$ \\
\hline Identify the decision criteria & 0.0 & 0.0 & 5.7 & 56.7 & 4.0 & 40.0 & 0.3 & 3.3 & 0.0 & 0.0 & 3.53 & $\begin{array}{l}\text { Medium } \\
\text { compliance }\end{array}$ \\
\hline Assign weights to the criteria & 0.0 & 0.0 & 1.0 & 10.0 & 5.7 & 56.7 & 3.3 & 33.3 & 0.0 & 0.0 & 2.77 & $\begin{array}{l}\text { Medium } \\
\text { compliance }\end{array}$ \\
\hline Develop the alternatives & 0.0 & 0.0 & 2.0 & 20.0 & 0.7 & 6.7 & 7.3 & 73.3 & 0.0 & 0.0 & 2.47 & $\begin{array}{l}\text { Medium } \\
\text { compliance }\end{array}$ \\
\hline Analyze alternatives & 0.0 & 0.0 & 1.7 & 16.7 & 7.0 & 70.0 & 1.3 & 13.3 & 0.0 & 0.0 & 3.03 & $\begin{array}{l}\text { Medium } \\
\text { compliance }\end{array}$ \\
\hline Selecting an Alternative & 0.0 & 0.0 & 4.0 & 40.0 & 6.0 & 60.0 & 0.0 & 0.0 & 0.0 & 0.0 & 3.40 & $\begin{array}{l}\text { Medium } \\
\text { compliance }\end{array}$ \\
\hline Implement the alternative & 0.0 & 0.0 & 3.0 & 30.0 & 6.7 & 66.7 & 0.3 & 3.3 & 0.0 & 0.0 & 3.27 & $\begin{array}{l}\text { Medium } \\
\text { compliance }\end{array}$ \\
\hline $\begin{array}{l}\text { Evaluate the effectiveness of } \\
\text { the decision }\end{array}$ & 0.0 & 0.0 & 3.7 & 36.7 & 6.3 & 63.3 & 0.0 & 0.0 & 0.0 & 0.0 & 3.37 & $\begin{array}{l}\text { Medium } \\
\text { compliance }\end{array}$ \\
\hline PEI & 0.1 & 1.3 & 3.2 & 31.7 & 5.0 & 50.4 & 1.7 & 16.7 & 0.0 & 0.0 & 3.18 & $\begin{array}{l}\text { Medium } \\
\text { compliance }\end{array}$ \\
\hline
\end{tabular}

S: Always, CS: Almost always, AV: Sometimes, CN: Almost Never, N: Never

the average was 2.77 which reflects a medium compliance and notes the absence of the attribute; occasionally the selection criteria is done by comparing each of the values according to the objectives that are chosen, the same occurs with the weighting of criteria for making a correct decision, and sometimes it is made an assessment of the objective function of each of the decisions taken. As soon argues that if the criteria identified do not have all the same weights together, who takes the decision has to weighting them in an orderly fashion to assign the correct priority in decision ${ }^{12}$.

For the indicator Develop alternatives, the $73.3 \%$ of the subjects surveyed opted for the alternative of almost never, and a $20 \%$ felt almost always; determining an average of 2.47 which indicates a medium level of compliance and the absence of the attribute; on this basis, we find that the deciding body prepares a list of sometimes viable alternatives to solve the problem, in the same way, the area manager occasionally proposes individually list alternatives for solving problems, also with moderate frequency managers to effect of increasing your creativity come to brainstorming sessions regardless that seem illogical. This explains why this fourth stage, who takes the decision to prepare a list of viable alternatives to resolve the problem ${ }^{12}$.

In relation to the indicator to analyze alternatives, the $70 \%$ of respondents indicated that the alternative at times, the $16.7 \%$ almost always and a $13.3 \%$ almost never, throwing an average of 3.03 which indicates a medium level of compliance, demonstrating the absence of the attribute; according to the results revealed that after identifying alternatives, sometimes who takes the decision analyzes in a critical way these options, with a moderate frequency the Manager evaluates the criteria that could contribute to solving the objectives previously raised by the department, also with this comparison will occasionally reveal the advantages of each alternative. These considerations do not relate after identifying alternatives, who takes the decision has to analyze critically, making comparisons that reveal the advantages and disadvantages of each alternative $e^{12}$.

With regard to the indicator to select an alternative, $60 \%$ of respondents felt that at times and the $40 \%$ pointed out that almost always, obtaining an average of 3.40 with medium compliance and absence of the attribute (Table 6), reflecting that managers do not always choose 
the best alternative among all considered, after weighing the decision criteria the manager sometimes chooses the alternative that generated greater weighting, it also happens that the decision-maker is moderately objective when it comes to selecting the best alternative. This does not explain that this sixth stage is to choose the best alternative among all considered. After weighing all the criteria of the decision and to analyze all viable alternatives, simply choose the one that generated the larger total in the fifth stage ${ }^{12}$. Regarding the indicator implement alternatives, a $66.7 \%$ felt at times, while $30 \%$ was the option of almost always, throwing an average of 3.27 which indicates a medium level of compliance and absence of the attribute (Table 8). Noting that the manager sometimes communicates the decision to create commitment to improving processes, the alternative implemented sometimes offers good results to the area where the processes, in the same way, the staff of the area moderately enthusiastically supports the result of the selected alternative. Also, the results mentioned above do not show congruence with a point raised by those who say that in Stage 7 starts the decision, which is to communicate it to those affected and to commit themselves with her ${ }^{12}$. If the people who must implement the decision to participate in the process, it is more likely to enthusiastically support the result that if only tells them what to do.

For the indicator to evaluate the effectiveness of the decision, the $63.3 \%$ of the subjects surveyed felt that at times and the $36.7 \%$ leaned by the option of almost always obtained an average of 3.37 pointing to a medium level of compliance and the absence of the attribute; demonstrating that the area manager sometimes evaluates the outcome of the decision in order to know if the issue is resolved, also the decision-making process efficient occasionally allows to improve conflict in the department, and with a moderate frequency if the evaluation of the decision shows failures, the manager examines them to perform the procedure again. This does not coincide with what is stated by those who express that this last stage of the process consists in evaluating the outcome of the decision in order to know if the problem is resolved. The responses will be returned to the manager to one of the previous stages, even you may need to repeat the whole process $^{12}$

Once studied, analyzed and interpreted the results presented above, it is stated that the $50.4 \%$ of the respondents opted for the alternative to fold, while $31.7 \%$ opted for the option almost always and a $16.7 \%$ leaned in almost never, determining an average of 3.18 which indicates a medium level of compliance and cataloguing the absence of the attribute; this is evidence that the universal bank does not take into account all stages present in the process for elements of implementation. Therefore, the results obtained do not relate to the position of those who expose that in decision-making the essence of the work of the manager, presents a series of eight stages that starts by identifying a problem, the decision criteria and weighting them, then develop alternatives, passes to analyze to select an alternative to solve the problem, finally evaluates the effectiveness of the decision, making the managers are those which form the decision-making process ${ }^{12}$.

For the Table 7, the results are displayed for the dimension conditions for decision-making, where it was shown for the indicator certainty, the highest percentage went to the alternative almost always with a $83.3 \%$ and the average 4.10 which indicates a high compliance and the presence of the attribute; noting that the manager makes decisions with precision because they know the result that will produce each alternative, similarly, in the department manages the exact information in order to achieve this objective, and in the agricultural area, decisions are made by providing the information required for solution. With

Table 8. Absolute frequency (n), relating (\%), stockings and categories of indicators associated with the conditions for decision-making - Centre for Training and Development (CTD) in banking institutions studied in the municipality of Maracaibo, Zulia State, Venezuela

\begin{tabular}{|l|c|c|c|c|c|c|c|c|c|c|c|l|}
\hline \multirow{2}{*}{ Indi-cators } & \multicolumn{2}{|c|}{ S } & \multicolumn{2}{|c|}{ CS } & \multicolumn{2}{c|}{ AV } & \multicolumn{2}{c|}{ CN } & \multicolumn{2}{|c|}{$\mathbf{N}$} & \multirow{2}{*}{ Media } & \multirow{2}{*}{ Category } \\
\cline { 2 - 12 } & $\mathbf{N}$ & $\mathbf{\%}$ & $\mathbf{N}$ & $\mathbf{\%}$ & $\mathbf{N}$ & $\mathbf{\%}$ & $\mathbf{N}$ & $\mathbf{\%}$ & $\mathbf{N}$ & $\mathbf{\%}$ & & \\
\hline Certainty & 1.3 & 13.3 & 8.3 & 83.3 & 0.3 & 3.3 & 0.0 & 0.0 & 0.0 & 0.0 & 4.10 & High Performance \\
\hline Risk & 1.3 & 13.3 & 5.3 & 53.3 & 3.0 & 30.0 & 0.3 & 3.3 & 0.0 & 0.0 & 3.77 & High Performance \\
\hline CTD & $\mathbf{1 . 3}$ & $\mathbf{1 3 . 3}$ & $\mathbf{6 . 8}$ & $\mathbf{6 8 . 3}$ & $\mathbf{1 . 7}$ & $\mathbf{1 6 . 7}$ & $\mathbf{0 . 2}$ & $\mathbf{1 . 7}$ & $\mathbf{0 . 0}$ & $\mathbf{0 . 0}$ & $\mathbf{3 . 9 3}$ & High Performance \\
\hline
\end{tabular}

S: Always, CS: Almost always, AV: Sometimes, CN: Almost Never, N: Never 
reference to the results shown, the same match the ideal situation to make decisions is the certainty, that is, the situation in which the manager can make correct decisions because they know the results of all alternatives ${ }^{12}$.

With regard to the risk was obtained that a $53.3 \%$ of the subjects surveyed was inclined to the alternative of almost always, to be the most frequent, obtained an average of 3.77 with high compliance and the presence of the attribute; indicating that the risk decisions are based on the perception of the risk of each individual, also in decision-making are evaluated parameters to establish the risk-return relationship, as well as handle historical data to assign probabilities to both economic and political alternatives. With regard to the foregoing, stated the described by those who argue that a situation much more common is the risk, in which who takes the decision estimates the probability of certain outcomes ${ }^{12}$. The ability to assign probabilities to the outcomes is the product of personal experiences or second-hand information, as well as historical data to assign probabilities to alternatives. As a general rule, in the dimension conditions for decisionmaking, it is envisaged that the highest percentage was in the alternative almost always with a $68.3 \%$, for an average of 3.93 wide compliance and presence of the attribute; demonstrating that the universal bank in Maracaibo creates the conditions of decision making to the problem.

In relation to the results shown in Table 9, referred to the variable financial decisions, it is explained that the greatest value obtained in the alternative was almost always with a $50 \%$, while the $33.5 \%$ of the subjects surveyed chose the option sometimes, obtaining an average of 3.55 reaching a level of medium compliance and cataloguing the absence of the attribute; reflecting that do not follow all the parameters for a financial decision-making due to the fact that the same is carried out in a medium compliance, i.e., nor do they fulfil the process, nor with the conditions for a sound financial decision-making. This differs with the theoretical postulate for whom financial decision-making, involves selecting, within a range or set of feasible alternatives, one that is emerging as the best, through a process of significant data collection, analysis, planning and financial control and implementation of the action required, for the solution of problems and achieving goals preset by the company ${ }^{13}$. Based on the foregoing, the correlation analysis indicated that there is a moderate direct relationship $(r=0.49)$ between the credit management and decision-making, consistent with high compliance and a medium compliance with each variable, respectively, in the universal bank studied.

\section{Conclusions}

The Financial Management of agricultural credits outlined a high presence in the universal bank in Maracaibo, while making decisions is considered as an attribute is absent from the approach being studied (processes and conditions), which showed a moderate direct correlation (positive) between these variables within the agricultural portfolio in universal banking of the municipality of Maracaibo, Zulia state Venezuela, which in other words indicates that it meets the parameters set for a good management, most do not follow all the parameters for a good financial decision-making. It is advisable to develop alternatives for decision-making relacionadas with credit, conduct meetings in the committees of credits on the improvement of internal rules and procedures for granting the credits through brainstorming; as well as you must also assess credit risk through the application of the identification of risk, the dose response relationship, the risk exposure, and perform a risk characterization.

Table 9. Absolute frequency (n), relating (\%), stockings and categories of financial decision-making in the granting of agricultural credit in banking institutions studied in the municipality of Maracaibo, Zulia State, Venezuela

\begin{tabular}{|c|c|c|c|c|c|c|c|c|c|c|c|c|}
\hline \multirow{2}{*}{ Dimensions } & \multicolumn{2}{|c|}{$S$} & \multicolumn{2}{|c|}{$\mathrm{CS}$} & \multicolumn{2}{|c|}{ AV } & \multicolumn{2}{|c|}{$\mathrm{CN}$} & \multicolumn{2}{|c|}{$\mathbf{N}$} & \multirow{2}{*}{ Media } & \multirow{2}{*}{ Category } \\
\hline & $\mathbf{N}$ & $\%$ & $\mathbf{N}$ & $\%$ & $\mathbf{N}$ & $\%$ & $\mathrm{~N}$ & $\%$ & $\mathbf{N}$ & $\%$ & & \\
\hline $\begin{array}{l}\text { Process for making elements of } \\
\text { implementation }\end{array}$ & 0.1 & 1.3 & 3.2 & 31.7 & 5.0 & 50.4 & 1.7 & 16.7 & 0.0 & 0.0 & 3.18 & Medium compliance \\
\hline Conditions for decision-making & 1.3 & 13.3 & 6.8 & 68.3 & 1.7 & 16.7 & 0.2 & 1.7 & 0.0 & 0.0 & 3.93 & High Performance \\
\hline Financial Decisions & 0.7 & 7.3 & 5.0 & 50.0 & 3.4 & 33.5 & 0.9 & 9.2 & $\mathbf{0 . 0}$ & 0.0 & 3.55 & Medium compliance \\
\hline
\end{tabular}

S: Always, CS: Almost always, AV: Sometimes, CN: Almost Never, N: Never 


\section{References}

1. Sotomayor AG, Barros SA. Los sistemas agroforestales en Chile. Chile: Instituto Forestal, Chile; 2016. p. 1-458.

2. Banesco. El Préstamo Agropecuario. Date accessed: 02.11.2018. http://www.banesco.com/personas/creditospersonas/creditos-agropecuarios/prestamo-agropecuarionaturales.

3. Gitman L, Zutter C. Principios de Administración Financiera. Decimo segunda edición. Pearson Educación, México; 2012. p. 1-720.

4. Muci G, Martín R. Regulación bancaria. UCaB, Caracas; 2004. p. 1-31.

5. Hernández Sampieri R, Fernández Collado C, Baptista Lucio P. Metodología de la investigación. 6a Edición. McGraw-Hill; 2014. p. 1-634.

6. Villase-or E. Créditos y Cobranzas. Lima, Perú: Pearson Educación; 2013.
7. República Bolivariana de Venezuela. Gaceta Oficial de la República Bolivariana de Venezuela; 2014.

8. República Bolivariana de Venezuela. Constitución Nacional de la República Bolivariana de Venezuela; 2000.

9. Hoyos K. Gestión Crediticia y riesgos financieros de la Banca Universal Venezolana en el Municipio Maracaibo. Trabajo de Grado para optar al Título de Magister en Gerencia Empresarial. [Maracaibo, Venezuela]: Universidad Rafael Belloso Chacín; 2013.

10. Albornoz A. Gestión Crediticia y Riesgo de la Cartera de Créditos Agropecuarios en la Banca Universal. En la Universidad Rafael Urdaneta Para Optar al Grado de MSc. en Banca y Finanzas; 2011.

11. Robbins SP, Decenzo DA, Coulter M. Fundamentos de administración. 8th Edition. México D.F.: Pearson Educación; 2013.

12. Perdomo A. Toma de decisiones financieras. México: Mc Graw Hill; 2004. 